Brit. Heart f., 1967, 29, 684.

\title{
Phonocardiographic Analysis of Diastolic Flow Murmurs in Secundum Atrial Septal Defect and Ventricular Septal Defect ${ }^{\star}$
}

\author{
ALEXANDER S. NADAS AND R. CURTIS ELLISON† \\ From the Sharon Cardiovascular Unit, Children's Hospital Medical Center, \\ and the Department of Pediatrics of Harvard Medical School, Boston, Mass., U.S.A.
}

The presence of low frequency diastolic murmurs, presumably due to increased flow through the respective atrio-ventricular valves, has been recognized in patients with atrial and ventricular septal defects for many years. The murmur in ventricular septal defect was reported by Laubry and Pezzi in 1921 and emphasized by Wood (1950). A publication from this institute drew attention to this phenomenon in atrial septal defect (Nadas and Alimurung, 1952).

The time of onset of this "rumbling" diastolic murmur was of some interest to one of us, and the clinical impression that the "flow rumble" of atrial septal defect occurs relatively early in ventricular diastole has been mentioned (Nadas, 1963). The present study was undertaken to investigate, by accurate phonocardiographic measurement, the validity of this bedside observation.

\section{SuBJECTS AND METHOdS}

Out of 200 phonocardiograms obtained in patients with the clinical diagnosis of secundum atrial septal defect or ventricular septal defect, 20 with each anomaly were selected for analysis on the basis of (1) presence of a diastolic rumble; (2) technically excellent tracing; (3) confirmation of the diagnosis at cardiac catheterization and/or open-heart surgery.

The patients ranged in age from 5 months to 23 years, and all had uncomplicated lesions. Of the 33 patients in whom left-to-right shunts were calculated at cardiac

Received September 5, 1966.

* Supported in part by grants from National Institutes of Health, Bethesda, Maryland, U.S.A., and the Massachusetts Heart Association.

† Ernest W. Lawson Fellow of the Massachusetts Heart Association, 1966-67. catheterization, the pulmonary to systemic flow ratio was greater than $2: 1$ in all but three instances.

The phonocardiograms were obtained in a soundproofed room on a Sanborn Polybeam, model 550M, photographic recorder with pre-amplifiers, model 3501700B. High pass filters with cut-off frequencies from 50 to 400 c.p.s., and a slope of 24 decibels per octave were used. The paper speed was $100 \mathrm{~mm}$. $/ \mathrm{sec}$. Recordings were obtained routinely along the upper and lower left sternal border and at the apex. Tracings were made during normal respiration, and during held expiration when possible. As reference, electrocardiograms, carotid artery and jugular venous pulse tracings, and apex cardiograms were utilized. The first heart sound was identified by the electrocardiogram and by the $N_{1}$ notch on the apex cardiogram. Aortic closure $\left(\mathrm{A}_{2}\right)$ was determined by its relation to the dicrotic notch on the carotid tracing. Pulmonary closure $\left(\mathbf{P}_{2}\right)$ was assumed to follow aortic closure and was registered well at the second left intercostal space. The third heart sound was identified by the "rapid filling" wave and the fourth sound by the " $a$ " wave on the apex cardiogram.

The following measurements were made by electrocardiographic calipers in each instance: (1) $A_{2}-P_{2}$ interval; (2) $\mathbf{A}_{2}$-onset of diastolic murmur; (3) $\mathbf{P}_{2}$-onset of diastolic murmur; (4) duration of diastolic murmur. All intervals were corrected for a rate of 60 . In addition to the above measurements, the area of maximal intensity of the murmur, any respiratory effects, and the presence or absence of a presystolic component were noted. The diastolic murmurs were all of low to medium frequency, usually best demonstrated with the 100 and 200 c.p.s. filters. The murmurs were always of moderate or low intensity; our present equipment does not lend itself to any more accurate estimation of this parameter.

The systolic murmurs, registered in all instances, are outside the scope of this paper and thus will not be discussed. 
TABLE

TIME RELATIONSHIPS OF DIASTOLIC MURMURS IN SECUNDUM ATRIAL SEPTAL DEFECT AND VENTRICULAR SEPTAL DEFECT

\begin{tabular}{|c|c|c|c|c|c|c|}
\hline $\begin{array}{l}\text { Case } \\
\text { No. }\end{array}$ & $\begin{array}{l}\text { Age } \\
(\mathbf{y r} .)\end{array}$ & $\begin{array}{l}\text { Heart } \\
\text { rate }\end{array}$ & $\underset{(\text { corrected) (sec.) }}{\mathbf{A}_{\mathbf{2}}-\mathbf{P}_{\mathbf{2}} \text { interval }}$ & $\begin{array}{c}\mathbf{A}_{2} \text {-onset diastolic murmur } \\
\text { (corrected) (sec.) }\end{array}$ & $\begin{array}{c}\mathbf{P}_{\mathbf{2}} \text {-onset diastolic murmur } \\
\text { (corrected) (sec.) }\end{array}$ & $\begin{array}{c}\text { Duration diastolic murmur } \\
\text { (corrected) (sec.) }\end{array}$ \\
\hline \multicolumn{7}{|c|}{ Atrial Septal Defect: } \\
\hline \multirow[t]{2}{*}{$\begin{array}{r}1 \\
2 \\
3 \\
4 \\
5 \\
6 \\
7 \\
8 \\
9 \\
10 \\
11 \\
12 \\
13 \\
14 \\
15 \\
16 \\
17 \\
18 \\
19 \\
20\end{array}$} & $\begin{array}{r}11 \\
10 \\
12 \\
9 \\
9 \\
5 \\
6 \\
9 \\
7 \\
13 \\
10 \\
16 \\
8 \\
13 \\
9 \\
23 \\
10 \\
5 \\
9 \\
6\end{array}$ & $\begin{array}{r}105 \\
75 \\
70 \\
92 \\
89 \\
111 \\
93 \\
79 \\
95 \\
90 \\
90 \\
79 \\
83 \\
79 \\
81 \\
78 \\
81 \\
98 \\
87 \\
93\end{array}$ & $\begin{array}{l}0.09 \\
0.08 \\
0.05 \\
0.05 \\
0.06 \\
0.09 \\
0.05 \\
0.06 \\
0.06 \\
0.06 \\
0.07 \\
0.05 \\
0.06 \\
0.06 \\
0.05 \\
0.09 \\
0.06 \\
0.04 \\
0.05 \\
0.06\end{array}$ & $\begin{array}{l}0.12 \\
0 \cdot 12 \\
0.11 \\
0 \cdot 10 \\
0 \cdot 10 \\
0 \cdot 14 \\
0.11 \\
0.10 \\
0 \cdot 11 \\
0 \cdot 12 \\
0 \cdot 13 \\
0.09 \\
0 \cdot 10 \\
0 \cdot 11 \\
0.12 \\
0.13 \\
0.10 \\
0.10 \\
0.11 \\
0.09\end{array}$ & $\begin{array}{l}0.03 \\
0.04 \\
0.06 \\
0.05 \\
0.05 \\
0.05 \\
0.06 \\
0.05 \\
0.05 \\
0.06 \\
0.07 \\
0.05 \\
0.04 \\
0.05 \\
0.07 \\
0.03 \\
0.04 \\
0.06 \\
0.06 \\
0.03\end{array}$ & $\begin{array}{l}0.13 \\
0.11 \\
0.17 \\
0.16 \\
0 \cdot 10 \\
0 \cdot 16 \\
0.13 \\
0.10 \\
0.16 \\
0.14 \\
0 \cdot 15 \\
0.12 \\
0.12 \\
0.12 \\
0.14 \\
0.16 \\
0.12 \\
0.13 \\
0.11 \\
0.11\end{array}$ \\
\hline & & & $\begin{array}{l}\text { Range }=0.04-0.09 \\
\text { Mean }=0.06\end{array}$ & $\begin{array}{l}\text { Range }=0.09-0.14 \\
\text { Mean }=0.11\end{array}$ & $\begin{array}{l}\text { Range }=0.03-0.07 \\
\text { Mean }=0.05\end{array}$ & $\begin{array}{l}\text { Range }=0.10-0.17 \\
\text { Mean }=0.13\end{array}$ \\
\hline \multicolumn{7}{|c|}{ Ventricular Septal Defect: } \\
\hline $\begin{array}{r}1 \\
2 \\
3 \\
4 \\
5 \\
6 \\
7 \\
8 \\
9 \\
10 \\
11 \\
12 \\
13 \\
14 \\
15 \\
16 \\
17 \\
18 \\
19 \\
20\end{array}$ & $\begin{array}{c}5 \\
8 \\
3 \\
10 \\
4 \\
5 / 12 \\
3 \\
9 \\
8 \\
9 / 12 \\
5 / 12 \\
7 \\
10 \\
4 \\
4 \\
1 \\
11 \\
5 \\
7 \\
8\end{array}$ & $\begin{array}{r}100 \\
81 \\
123 \\
133 \\
100 \\
123 \\
76 \\
89 \\
89 \\
136 \\
100 \\
87 \\
85 \\
120 \\
83 \\
170 \\
93 \\
75 \\
89 \\
64\end{array}$ & $\begin{array}{l}0.03 \\
0.09 \\
0.06 \\
0.06 \\
0.04 \\
0.04 \\
0.03 \\
0.02 \\
0.05 \\
0.03 \\
0.02 \\
0.04 \\
0.04 \\
0.04 \\
0.02 \\
0.04 \\
0.03 \\
0.02 \\
0.06 \\
0.05\end{array}$ & $\begin{array}{l}0.13 \\
0.19 \\
0.14 \\
0.21 \\
0.14 \\
0.11 \\
0.14 \\
0.15 \\
0.16 \\
0.12 \\
0.12 \\
0.13 \\
0.11 \\
0.11 \\
0.14 \\
0.11 \\
0.15 \\
0.13 \\
0.18 \\
0.15\end{array}$ & $\begin{array}{l}0.10 \\
0.09 \\
0.08 \\
0 \cdot 15 \\
0 \cdot 10 \\
0.08 \\
0 \cdot 11 \\
0 \cdot 12 \\
0 \cdot 11 \\
0.09 \\
0 \cdot 10 \\
0 \cdot 10 \\
0.07 \\
0.07 \\
0.12 \\
0.07 \\
0.13 \\
0.11 \\
0.12 \\
0.09\end{array}$ & $\begin{array}{l}0 \cdot 16 \\
0.14 \\
0 \cdot 13 \\
0 \cdot 15 \\
0 \cdot 17 \\
0 \cdot 14 \\
0 \cdot 15 \\
0 \cdot 16 \\
0 \cdot 13 \\
0 \cdot 12 \\
0 \cdot 13 \\
0 \cdot 13 \\
0 \cdot 14 \\
0 \cdot 16 \\
0 \cdot 17 \\
0 \cdot 11 \\
0 \cdot 16 \\
0 \cdot 13 \\
0.13 \\
0.13\end{array}$ \\
\hline & & & $\begin{array}{l}\text { Range }=0.02-0.09 \\
\text { Mean }=0.04\end{array}$ & $\begin{array}{l}\text { Range }=0.11-0.21 \\
\text { Mean }=0.14\end{array}$ & $\begin{array}{l}\text { Range }=0.07-0.15 \\
\text { Mean }=0.10\end{array}$ & $\begin{array}{l}\text { Range }=0 \cdot 11-0.17 \\
\text { Mean }=0.14\end{array}$ \\
\hline
\end{tabular}

\section{RESULTS}

The pertinent measurements are summarized in the Table and the characteristic time intervals are shown in Fig. 1. Fig. 2 and 3 show typical examples of the phonocardiograms studied.

As is evident from the Table and Figures, the diastolic flow murmur of the patient with atrial septal defect begins earlier in diastole than that of the patient with ventricular septal defect. The onset of the murmur, in relation to $A_{2}$, was found to occur on the average $0.03 \mathrm{sec}$. earlier in patients with atrial septal defect. More striking, however, is the average difference in the onset of the murmur 

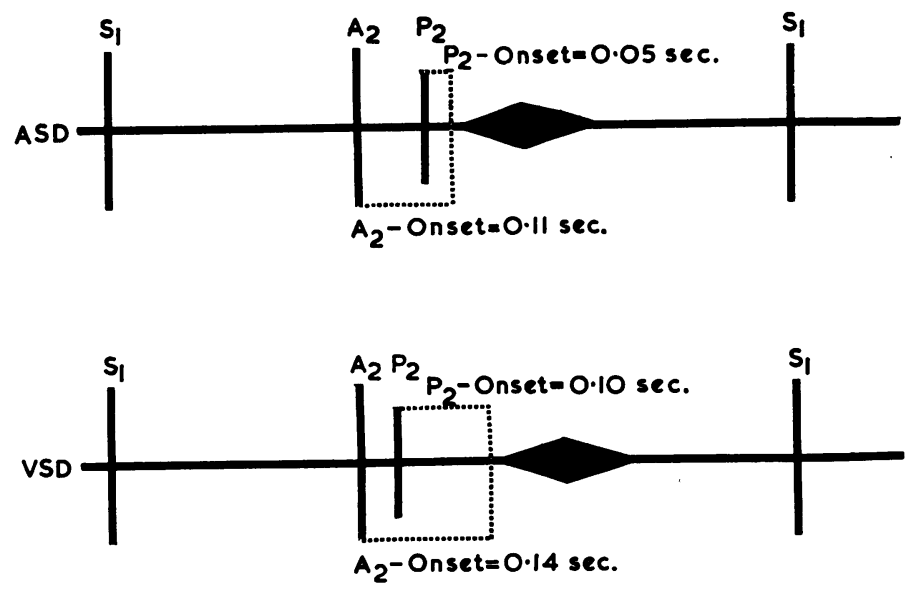

All intervals corrected to rote 60.

FIG. 1.-Diagrammatic representation of the typical time relationships of the diastolic flow murmurs in atrial septal defect and ventricular septal defect.
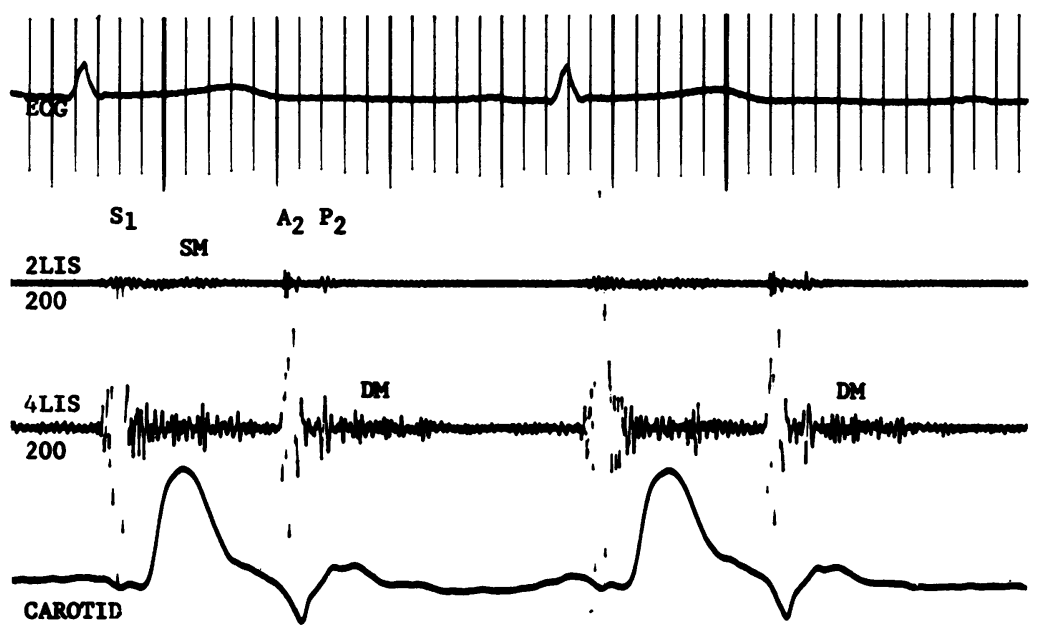

FIG. 2.-Tracing from patient with secundum atrial septal defect. The diastolic flow murmur (DM) begins in early diastole, shortly after the pulmonary component of the second sound $\left(\mathrm{P}_{2}\right)$. The tracing was taken with the 200 c.p.s. filter (SM= systolic murmur, 2LIS = second left intercostal space).

13 of 20 atrial and 17 of 20 ventricular septal defects. In no case did the presystolic murmur rise in a crescendo fashion to the first sound. Inspiration caused a slight increase in intensity of the diastolic murmur in most of the patients with atrial defect, but had no discernible effect on the murmur in those with ventricular defect. A third heart sound preceded the diastolic murmur in the majority of the latter group, but was uncommon in the patients with the former. A fourth heart sound was seen in only 2 of the 40 patients.

\section{Discussion}

Intracardiac phonocardiography has provided support for the theory that the diastolic "flow rumble" of atrial septal defect originates at the tricuspid valve and that of ventricular septal defect at the mitral valve (Liu and Jacono, 1958; Feruglio and Sreenivasan, 1959; Feruglio and Gunton, 1960). It is commonly accepted that the presence of a "flow rumble" indicates a rather large left-to-right shunt (Wood, Magidson, and Wilson, 1954; Leatham and Segal, 1962; Segal, Novack, and Kasparian, 1964). 


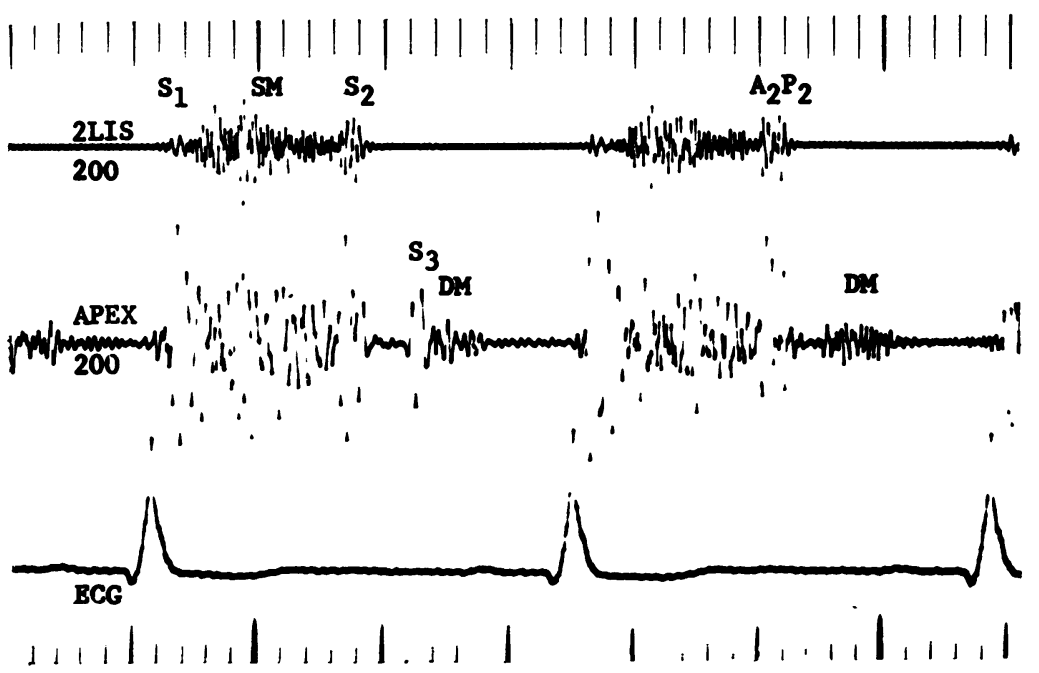

FIG. 3.-Tracing from patient with ventricular septal defect. The diastolic murmur, preceded by a third heart sound $\left(\mathrm{S}_{3}\right)$, occurs following a pause after $\mathbf{P}_{2}$.

Although an earlier report from this institute did not find a close correlation between the presence of a diastolic murmur and a large ventricular shunt (Fyler et al., 1958), it is interesting to note that in the present series, 30 of the 33 patients who were catheterized had pulmonary to systemic flow ratios greater than 2:1.

In the differential diagnosis of diastolic murmurs in patients with atrial or ventricular left-to-right shunts, those occurring in early diastole are usually separated from those registered in mid-diastole or presystole. The high frequency protodiastolic murmurs radiating from the base of the heart are properly attributed to semilunar incompetence. In patients with severe pulmonary hypertension, they suggest pulmonary regurgitation; in those with ventricular septal defect, a wide pulse pressure; and in those without pulmonary hypertension, aortic incompetence. A loud, low frequency protodiastolic murmur, preceded by an equally loud systolic murmur at the lower left sternal border, giving a "sawing wood" effect, is characteristic of the absent pulmonary valve syndrome, with ventricular septal defect but without pulmonary hypertension (Onesti and Harned, 1958; Miller, White, and Lev, 1958; Venables, 1962). Somerville and Resnekov (1965) have reported an "immediate diastolic murmur" in atrio-ventricular defects with mitral regurgitation and a gradient between the atria. In these cases, studies revealed the origin of the murmur to be at the atrial septal defect.

The mid-diastolic and presystolic murmurs of patients with left-to-right shunts are always of low to moderate frequency. Semilunar incompetence thus does not enter the differential diagnosis. Structural abnormalities of the mitral valve were long considered the usual causative factor (Lutembacher, 1916), but the rarity of cases of the Lutembacher syndrome proven at necropsy in most geographical areas casts doubt on this assumption (Nadas and Alimurung, 1952). Torrential flow across the atrio-ventricular valves is now generally accepted as the cause of the "flow rumbles" in patients with septal defects (Wood, 1950; Leatham and Gray, 1956; Feruglio and Sreenivasan, 1959; Feruglio and Gunton, 1960).

The data presented in this paper suggest that the timing of the diastolic murmur should not be the principal basis for differentiating semilunar incompetence from increased atrio-ventricular valve flow in patients with septal defects. The location, moderate or low intensity, and low to medium frequency, coupled with other evidence of a left-to-right shunt, should identify the flow murmur, whether it occurs in early or mid-diastole. Moreover, the occurrence of this "flow rumble" in early diastole is typical of atrial septal defect. It is probable that in patients with atrial defects, many murmurs previously felt to represent pulmonary incompetence, just because they occurred in early diastole, were actually only flow murmurs originating at the tricuspid valve.

It should be pointed out that the relatively early appearance of the flow murmur in patients with atrial septal defect is partially due to the wide split of the second sound commonly seen in these 
patients, the lateness of the pulmonary component of the second sound making the onset of the murmur appear earlier. However, this "auscultatory illusion" is of real diagnostic importance at the bedside, where the rumble in the atrial defect seems to start very soon after the $P_{2}$, while that in ventricular defect begins after a pause.

Even when measured from the aortic component of the second sound, however, the tricuspid "flow rumble" is actually slightly earlier than the mitral flow murmur. This may well be due to the tricuspid valve opening earlier than the mitral valve. Reinhold and Rudhe (1957) in their electrokymographic studies in normal people found supportive evidence for this time sequence, and the earlier appearance of the opening snap of tricuspid stenosis than that of mitral stenosis has been mentioned (Tafur, Cohen, and Levine, 1964). It seems logical that the right atrial pressure would open the tricuspid valve, held shut by the lower right ventricular diastolic pressure, earlier than the left atrial pressure would overcome the higher left ventricular diastolic pressure. It is interesting to note that Reinhold and Rudhe placed tricuspid valve opening approximately $0.03 \mathrm{sec}$. before mitral valve opening, a difference identical with that found in this study between the onset of the atrial and ventricular septal defect flow murmurs.

Finally, it should be stressed that the low frequency diastolic murmur of left-to-right shunts may have a presystolic component. The absence of a crescendo component could aid in differentiating this phenomenon from the murmur of mitral or tricuspid stenosis.

\section{SUMMARY}

Diastolic flow murmurs in 20 patients with secundum atrial septal defects and 20 patients with uncomplicated ventricular septal defects were analysed from phonocardiographic tracings. The onset of the "flow rumble" in the patients with atrial septal defect was found to occur 0.03 to 0.07 sec. (mean $=0.05 \mathrm{sec}$.) after the pulmonary component of the second sound $\left(\mathrm{P}_{2}\right)$, while that in the patients with ventricular septal defect was 0.07 to $0.15 \mathrm{sec}$. (mean $=0.10 \mathrm{sec}$.) after $\mathrm{P}_{2}$. The difference of the means is statistically significant $(p<0.001)$.

The relative earliness of the murmur in atrial septal defect is partially an auscultatory illusion; the delayed pulmonary second sound, usually found in these patients, makes the onset of the murmur appear earlier. Nevertheless, this short interval is useful clinically and can usually be discerned at the bedside.
The separation of flow murmurs from other diastolic murmurs (representing semilunar valve incompetence, associated mitral valve disease, etc.) in patients with atrial and ventricular septal defects is discussed. Since flow rumbles may occur in early diastole, it is suggested that in the differential diagnosis of diastolic murmurs in these patients, characteristics other than the timing of the murmur be used to determine the ætiology.

\section{REFERENCES}

Feruglio, G. A., and Gunton, R. W. (1960). Intracardiac phonocardiography in ventricular septal defect. Circulation, 21, 49.

- , and Sreenivasan, A. (1959). Intracardiac phonocardiogram in thirty cases of atrial septal defect. Circulation, $20,1087$.

Fyler, D. C., Rudolph, A. M., Wittenborg, M. H., and Nadas, A. S. (1958). Ventricular septal defect in infants and children. Circulation, 18, 833.

Laubry, C., and Pezzi, C. (1921). Traité des Maladies Congénitales du Cour. Baillière, Paris. (Quoted by Wood, Magidson, and Wilson, 1954.)

Leatham, A., and Gray, I. (1956). Auscultatory and phonocardiographic signs of atrial septal defect. Brit. Heart F., 18, 193.

$\longrightarrow$, and Segal, B. (1962). Auscultatory and phonocardiographic signs of ventricular septal defect with left-toright shunt. Circulation, 25, 318.

Liu, C. K., and Jacono, A. (1958). Phonocardiography in atrial septal defect. Amer. F. Cardiol., 2, 714.

Lutembacher, R. (1916). De la sténose mitrale avec communication interauriculaire. Arch. Mal Cour, 9, 237.

Miller, R. A., White, H., and Lev, M. (1958). Congenital absence of the pulmonary valve: clinical and pathological syndrome. Circulation, 18, 759 (abstract).

Nadas, A. S. (1963). Pediatric Cardiology, 2nd ed. W. B. Saunders, Philadelphia.

-, and Alimurung, M. M. (1952). Apical diastolic murmurs in congenital heart disease. Amer. Heart f., 43, 691.

Onesti, S. J., and Harned, H. S. (1958). Absence of the pulmonary valve associated with ventricular septal defect. Amer. F. Cardiol., 2, 496.

Reinhold, J., and Rudhe, U. (1957). Relation of the first and second heart sounds to events in the cardiac cycle. Brit. Heart f., 19, 473.

Segal, B. L., Novack, P., and Kasparian, H. (1964). Intracardiac phonocardiography. Amer. F. Cardiol., 13, 188.

Somerville, J., and Resnekov, L. (1965). The origin of an immediate diastolic murmur in atrioventricular defects. Circulation, 32, 797.

Tafur, E., Cohen, L. S., and Levine, H. D. (1964). The normal apex cardiogram. Its temporal relationship to electrical, acoustic, and mechanical cardiac events. Circulation, 30, 381.

Venables, A.W. (1962). Absence of the pulmonary valve with ventricular septal defect. Brit. Heart F., 24, 293.

Wood, P. (1950). Congenital heart disease: A review of its clinical aspects in the light of experience gained by means of modern techniques. Brit. med. F., 2, 639.

$\longrightarrow$, Magidson, O., and Wilson, P. A. O. (1954). Ventricular septal defect; with a note on acyanotic Fallot's tetralogy. Brit. Heart f., 16, 387. 